\title{
Assessment of Probiotic Potential Leuconostoc Mesenteroides from Natural Microbiota
}

\author{
Sathyapriya $\mathrm{A}^{1 *}$, Anitha $\mathrm{A}^{2}$ \\ ${ }^{1,2}$ Department of Biotechnology, Nehru Arts and Science College, Coimbatore - 641 105, Tamil Nadu, India \\ *Corresponding author: priyabio17@gmail.com_8508063022
}

Available online at: www.isroset.org

Received: 23/Oct/2018, Accepted: 26/Nov/2018, Online: 31/Dec/2018

\begin{abstract}
A Lactic Acid Bacterium (LAB) is a group of Gram-positive, non-spore forming, motile microorganisms, highly in fermented foods and are well known for their probiotic properties. A heterofermentative lactic acid bacterium, primarily of Leuconostoc mesenteroides from the natural microbiota (sauerkraut fermentation) was isolated, and identified by conventional biochemical characteristics and 16S rDNA gene sequence analysis. Based on the above the isolated natural microbiota was identified as Leuconostoc mesenteroides and deposited in MCC for general access (MCC 3276). The isolated strain had the ability of tolerate bile salts and expressed resistance towards low $\mathrm{pH}$. The ability of bacterial isolates showed autoaggregation and coaggregation which is directly related it adherence capability into the intestinal wall which might have competed with undesirable microorganism in the gut.The tolerance to various biological barriers such as lysozyme $(100 \mu \mathrm{g})$, gastric juice $(\mathrm{pH} 3.0)$ and bile salt $(0.5 \% \mathrm{w} / \mathrm{v})$ were confirmed its ability to survive extreme conditions of digestive tract. L. mesenteroides has no clear transparent zone in blood agar plates and thus were found non-hemolytic. Overall results indicated that the isolate, Leuconostoc mesenteroides, might be an attractive candidate for perspectival strain for probiotics.
\end{abstract}

Keywords: Sauerkraut fermentation, Leuconostoc mesenteroides, Biological characteristic, Molecular identification, Probiotics.

\section{INTRODUCTION}

With the development of commercial scale aquaculture, it has become apparent that diseases are the significant limiting factor. Chemotherapeutic agents, i.e. antibiotics, could lead to the evolution of resistance among pathogenic bacteria and probiotic, may reduce the incidence of disease outbreaks as the substitution for chemotherapeutic agents [1]. Probiotic is associated with the beneficial effects for humans and animals. These microorganisms contribute to intestinal microbial balance and playing an important role in maintaining health. Lactobacillus sp., and Bifidobacterium sp., are a major part of the probiotics micro flora of the intestine and of fermented products, and are found in a variety of environments [2].

The Lactic Acid Bacteria (LAB), is a group of Grampositive, non-spore forming, motile microorganisms are well known for their probiotic properties. They can produce inhibitory compounds such as lactic acid, bacteriocin and hydrogen peroxide preventing the growth of harmful microbes. Several kinds of facultatively anaerobic lactic acid bacteria participate in the fermentation of vegetables. Among these bacteria Leuconostoc mesenteroides, Lactobacillus plantarum and Lactobacillus brevis are the most important and they are naturally present in vegetables [3]. In natural fermented foods, fermentation is consistently initiated by heterofermentative lactic acid bacteria (LAB), primarily Leuconostoc mesenteroides [4] and used as probiotic in aquaculture. The mechanism of LAB as probiotics includes the production of inhibitory substances against pathogen, competition for essential nutrients, adhesion sites and tolerance for $\mathrm{pH}$ and bile in stomachintestinal tract[5]. Consequently, in present study a lactic acid bacterium Leuconostoc mesenteroides from the natural microbiota had remained isolated and identified as per biochemical, molecular characteristics. Selected probiotic strains were also investigated for their biological characteristics and probiotic efficacy was evaluated for its potential applications in marine aquaculture.

\section{MATERIALS AND METHODS}

\subsection{ISOLATION OF PROBIOTIC ORGANISM}

2.1.1. Fermentation by natural microbiota

To prepare sauerkraut, fresh cabbages (organically farmed) were purchased from Sreevatsa Organic Farm Products, Coimbatore, Tamil Nadu, India, during 2016. Laboratory fermentations of cultivars of cabbages were conducted in Phyto Jar. Fermentation medium was prepared by removing 
the outer leaves and core of cabbages, cutted in to $1 / 16$-inch slicing disk. The shredded cabbages were salted with $2-2.5$ $\%$ (w/v) of $\mathrm{NaCl}$ solution (brining solution i.e. rough sea salt) and all together was pressed tightly and covered with a plastic film. Triplicates were maintained and the jars were incubated at room temperature for fermentation by natural micro-biota associated with cabbages [6].

\subsubsection{Isolation of lactic acid bacteria}

For the isolation of LAB, brines were sampled after 4 days of single laboratory fermentation and plated onto MRS agar, incubated aerobically at $30^{\circ} \mathrm{C}$ for 4 days. Two uncrowded viscous colonies presumed to be Leuconostoc sp., were picked up randomly from MRS agar plates and purified by streaking on MRS plate. The isolated pure culture was subcultured and stored at $4^{\circ} \mathrm{C}$ in $10 \%$ glycerol for further use [7].

\subsubsection{Phenotypic identification of isolated probiotics}

An array of biochemical test for determining the phenotypic profile of the isolated probiotics were carried as per Bergey's Manual of Systematic Bacteriology [8]. The isolated microorganism was deposited in general deposition of Microbial Cell Culture (MCC) for open access.

\subsection{PROBIOTIC POTENTIAL OF LEUCONOSTOC MESENTEROIDES}

The hydrophobic, auto aggregation behavior, lysozyme [3], Coaggregation [5], effect of $\mathrm{pH}$ on survival rate, bile salt tolerance [9] and Hemolytic assay [10] of L. mesenteroides were assessed for evaluating the probiotic potential.

\subsection{MOLECULAR IDENTIFICATION OF} ISOLATE

2.3.1. DNA isolation, PCR amplification and gene sequencing

Genomic DNA from Leuconostoc mesenteroides was extracted according to Manufacturers instruction (BioBeeTechPvt. Ltd., Karnataka, India). The quantitation of extracted DNA was estimated by 260/280 ratio using spectrophotometer while the integrity was visualized on $1 \%$ agarose gel with the help of UVTransilluminator(Biotech R\&D Laboratories, Tamil Nadu, India). Universal primer (forward primer- 5' GAGTTTGATCMTG and reverse primer- 5' AGAGTTTGATCMT) targeted for 16s rRNA have been employed for the molecular level identification of Leuconostocmesenteroides. 16s rRNA amplification program were conducted as follows: $94^{\circ} \mathrm{C}$ for 1 min,30 cycles, at $94^{\circ} \mathrm{C}$ for $30 \mathrm{sec}, 50^{\circ} \mathrm{C}$ for $30 \mathrm{sec}$ and $72^{\circ} \mathrm{C}$ for $1 \mathrm{~min}$ with a final extension step of $72^{\circ} \mathrm{C}$ for $10 \mathrm{~min}$. For $\mathrm{PCR}$ experiment, gradient Mastercycler (Ependorf Scientific Inc, Westbury, NY, USA) was used with a reaction mixture comprising of $5 \mu$ lofisolated DNA, $1.5 \mu$ of Forward Primer and Reverse Primer, $12 \mu \mathrm{l}$ of TaqMasterMix (Taq DNA polymerase is supplied in $2 \times$ Taq buffer, $0.4 \mathrm{mM}$ - dNTPs,
$3.2 \mathrm{mM}-\mathrm{MgCl} 2$, and $0.02 \%$-bromophenol blue)and $5 \mu \mathrm{l}$ of deionized water.The resulting amplified PCR products were visualized on $0.8 \%$ agarose gelelectrophoresis with Marker DNA using 1×TAE Buffer. The resulting DNA patterns were examined under gel documentation and the photographs were documented (Bio-Rad, USA).

\subsubsection{Purification and sequencing of PCR product} Unincorporated PCR primers and dNTPs from PCR products were removed by usingMontage PCR Clean up kit (Millipore, US).Single-pass sequencing was performed on eachtemplate using $16 \mathrm{~s}$ rRNA universal primers. Sequencing reactions were performed using a ABI PRISM®BigDyeTM Terminator Cycle Sequencing Kits with AmpliTaq ${ }^{\circledR}$ DNA polymerase (FS enzyme) (Applied Biosystems, US).The fluorescent-labeled fragments were purified from the unincorporated terminators with an ethanol precipitation protocol. The samples were resuspended in distilled water, subjected to electrophoresis in an ABI 3730xl sequencer (Applied Biosystems, US) and the resulting chromatogram was documented.

\subsubsection{Multiple sequence alignment and phylogenetic analysis}

The obtained 16s rRNA sequence was subjected to nucleotide blast using NCBI blastsimilarity search tool. The program MUSCLE 3.7 rendered the multiple sequence alignments for closely related gene sequences [11].The resulting aligned sequences were trimmed using the program Gblocks $0.91 \mathrm{~b}$ for eliminating poorly aligned positions and divergent regions [12]. Finally, the program PhyML 3.0 aLRT was used for phylogeny analysis having HKY85 as substitution model. PhyML was shown to be at least as accurate as other existing phylogeny programs using simulated data, while being one order of magnitude faster. PhyML was shown to be atleast as accurate as other existing phylogeny programs using simulated data, while be in gone order of magnitude faster. The program Tree Dyn 198.3 was used for tree rendering [13].

\section{RESULTS AND DISCUSSION}

\subsection{Isolation of probiotics}

The sliced cabbages were salted with $2-2.5 \%$ (w/v) of $\mathrm{NaCl}$ solution for sauerkraut fermentation, incubated in the air tight container. After 4 days, brine sample were sampled and plated onto MRS agar and incubated (Fig. 1). The viscous colonies presumed to be Leuconostoc sp., were picked up and stored at $4^{\circ} \mathrm{C}$ as glycerol stock for further identification. Based on Bergey's Manual of Systematic Bacteriology the isolated natural microbiota were identified as Leuconostoc mesenteroides and the voucher specimen was deposited (MCC 3276) (Tab-1). Similarly, previous studies have used both culture- and sequencing-based methods to elucidate the fermentative microbial community of sauerkraut. Culture-based methods have shown that the 
major LAB involved in sauerkraut fermentation are belongs to E. faecalis, L. mesenteroides, L. brevis, $P$. cerevisiae, and L. plantarum; while sequencing-based methods highlighted the Lactobacillus sp., and Leuconostoc sp., in addition to Weissella [14, 15]. Likewise, the isolation of $L$. mesenteroides were carried out from the natural fermented medium, probiotic potential and its survival under the bile salt conditions has also been reported [3]. Whereas, the probiotics like Lactobacillus sp., Arthobacter sp., and Bacillus sp., have showed their effective response towards the pathogens [16]. This study revealed that $L$. mesenteroides strains are present during the heterofermentative stage of sauerkraut fermentation and long been considered to be the preponderant species during the first week of fermentation.

\subsection{Molecular identification of selected probiotic}

The morphological characteristics of the isolate placed the organism belongs to Leuconostoc mesenteroides. This was confirmed by $16 \mathrm{~S}$ rDNA gene sequence analysis. Genomic DNA was amplified using a gradient PCR and the electrophoretic patterns obtained in this study showed that the primers (16S rDNA) used, successfully amplified the conserved region in our gene of interest in the selected isolate. The size of the amplified product was about $960 \mathrm{bp}$ in length. The phylogenetic tree based on multiple sequence alignment was constructed by using phyML. In LAB isolated from the middle stage of fermentation, displayed 98\% homology with Leuconostoc mesenteroides, sequences were determined to share $96 \%$ homology (Fig 2). The 16S rDNA gene sequence of the isolate was deposited in GenBank under accession number is MF927885 respectively. Likewise, several authors have exposed similar results $[5,9]$.

\subsection{Probiotic potential of $L$. mesenteroides}

Hydrophobicity and auto-aggregation of microorganism are phenotypically related to its adhesion capacity to intestinal epithelial cells $[17,18]$. It is the hydrophobic nature of outer layer of microbe which helps in attaching to the mammalian cell surface [19]. The adhesion property also supports a probiotic microbe to compete with other microorganisms in gastrointestinal tract. The hydrophobicity of $L$. mesenteroides (MCC 3276) was $46.6 \%$ after 20 mins (Fig $3)$. This was significantly higher than other reported probiotic bacteria such as Lactococcus aidoplilus (38.1\%), Lactococcus casei $(24.1 \%)$ and Lactococcus lactis (31.3\%) (3). In the same track, L. mesenteroides could autoaggregate itself with a percentage increased from $14.2 \%$ to $38.0 \%$ during 0-5 hrs (Fig 4). According to previous reports, autoaggregation capability of $L$. lactics was very normal which showed the percentage of $7.8 \%$ to $23.29 \%$ during 2$20 \mathrm{hrs}$ (5). In conclusion, compared with other probiotics L. mesenteroides exposed higher percentage.
Coaggregation abilities may form a barrier that prevents colonization by pathogenic microorganisms. Coaggregation with pathogen may constitute an important host defense mechanism against infection [20]. In the study, coaggregation of the L. mesenteroides with pathogen was examined and it showed that the $L$. mesenteroides coaggregated the pathogen and coaggregation percentage which increases with the prolongation of incubation time from $0^{\text {th }}$ to $5^{\text {th }} \mathrm{h}$. After $5^{\text {th }} \mathrm{h}$ of incubation of a mixed suspension, the isolate coaggregated the cholerae with the high percentage (23\%) (Fig 3). The bacterial autoaggregation and coaggregation were beneficial properties, which were respectively related to cell adherence and inhibition against pathogen, and played an important role in intestinal tract. Although, L. lactic coaggregated the enteropathogens with the high percentage for $V$. parahaemolyticus $(31.21 \%)$ and L. monocytogenes (29.44\%), the middle coaggregation percentages for Shigella (24.36\%), S. aureus (24.41\%) and P. vulgaris (20.99\%), and the low coaggregation percentages for E. coli $\mathrm{O} 157$ $(10.74 \%)$ and S. typhimurium (16.49\%) were reported in literature [5]. The isolate could have the ability of aggregating itself and coaggregating other bacteria.

In order to evaluate the ability of bacterial isolates to support stomach aggressive conditions, isolate was exposed to different concentrations $(0.0,0.15$ and $0.3 \%)$ of bile salt to find out tolerance of $L$. mesenteroides. It showed not only viability but also proliferation in different concentrations for all the incubation periods. L. mesenteroides had bile tolerant and may look to have high potential to adhere as a desirable probiotic because as bile salt concentration increased, the growth rate of $L$. mesenteroides decreased significantly. The more proliferation was observed at $4^{\text {th }}$ and $8^{\text {th }} \mathrm{h}$ of incubation period (Fig. 5). Likewise, the previous study determined that $L$. plantarum as a probiotic could survive in $0.3 \%$ of bile salt [21]. Nguyenet al.., [22] reported the growth of L. plantarum $\mathrm{PH} 04$ in bile salt ranging from 0 to $0.4 \%$. Similarly, Lactobacillus acidophilus resisted high concentration (2\%) of bile, which could be due to its adaptation to the low $\mathrm{pH}$ environment and hence decreasing the toxicity in the intestine [21]. Tolerance to bile is important for the probiotic strains to grow and survive in the digestive tract. The probiotics that can tolerate low $\mathrm{pH}$ and bile salt indicated that they not only can transit through stomach and be active in intestine but also able to be alive and survive in stress conditions [23]. Furthermore, this strain showed different ability to survive and grow in bile salt. Bile salt tolerance is required for probiotic bacteria to grow and survive in intestine [24].

$\mathrm{pH}$ value is one of aspects in prompting survival of bacteria in gastric juice, and so the different $\mathrm{pH}$ ranges were examined about its effect on the survival of bacteria. In this present study, $\mathrm{pH}$ tolerance indicated that the growth rate (optical density) of L. mesenteroides changed significantly 
from $\mathrm{pH} 2$ to 6 . This L. mesenteroides did not have any activity and viability at $\mathrm{pH} 2$ after $2 \mathrm{~h}$ incubation but, presented viability and growth at $\mathrm{pH} 2.5$ and more. The growth rate of $L$. mesenteroides increased from $\mathrm{pH} 3$ to 6 . The lowest viability and growth were obtained at $\mathrm{pH} 2$ and the highest at pH 6 (Fig. 6). The study showing, survival and growth at low $\mathrm{pH}$ confirm that this isolate can transit through stomach. According to previous reports the strains of Pediococcus acidilactici (P2), Lactobacillus curvatus (RM10), and P. pentosaceus (FF) showed tolerance to acid $(\mathrm{pH} 3.0)$ [25]. One of the most important criteria for selection of $\mathrm{LAB}$ as probiotic is potential viability at low $\mathrm{pH}$ [26].

The lack of $\gamma$-haemolytic activity is a desirable trait in probiotic bacteria. Hemolytic assay of $L$. mesenteroides has no clear transparent zone on the blood agar plates, surrounding their colonies, and thus were found nonhemolytic ( $\gamma$-haemolytic). The absence of haemolytic activity are considered safety prerequisites for the selection of a probiotic strain [27]. The present study was supported by many authors $[28,9]$.

The resistance of L. mesenteroides to lysozyme expressed as percent. It showed resistance to $100 \mu \mathrm{g} / \mathrm{ml}$ of lysozyme with $90 \%$ survivals after $2 \mathrm{~h}$ as compared to control having $1.45 \mathrm{x}$ $10^{6} \mathrm{CFU} / \mathrm{ml}$ (Fig 3). It was in good agreement with previously reported lysozyme resistance data of other probiotic bacteria such as Lactobacillus plantarumLp793 (87.85\%), L. plantarum Lp800 (84.69\%) and L. plantarum Lp813 (74.04\%) [19]. The accepted probiotic microorganisms generally encounter first biological barrier of lysozyme, which is present in saliva of mouth. The next barrier is gastric juice in stomach, where the $\mathrm{pH}$ is between 1.5 and 3.0 and the upper part of small intestine, which contains bile (3).

\section{CONCLUSION}

In this study, the strain of lactic acid bacteria, Leuconostoc mesenteroides, isolated from natural microbiota, could be better adaptive to survivorship and colonization in the intestinal tract in accordance with its hydrophobicity, aggregation, ability and tolerance for $\mathrm{pH}$, bile, lysozyme conditions. The coaggregation assay indicated its potentially probiotic properties. The above results indicated that the isolate, Leuconostoc mesenteroides (MCC 3276), could be used as the perspectival strain for probiotics in marine aquaculture.

\section{REFERENCES}

[1]. K. G. Deshpande, C.B. Dolas, N.S. Chavan, "Investigation of tolerance of acids, bile salts and deconjugation of bile salts", International journal of current Microbiology and Applied sciences, Vol. 3, Issue. 7, pp. 600-612, 2014.
[2]. Carlos Ricardo Soccol, Luciana Porto de Souza Vandenberghe, Michele Rigon Spier,Adriane Bianchi Pedroni Medeiros, Caroline TiemiYamaguishi, Juliano De Dea Lindner, Ashok Pandey and Vanete Thomaz- Soccol, "The Potential of Probiotics",Food Technology and Biotechnology ,Vol. 48 ,Issue.4,pp. 413434,2010.

[3]. RishikeshShukla, Ilia Ilie, \&Arun Goyal, "Leuconostoc mesenteroides NRRL B-1149 as probiotic and its dextran with anticancer properties", Journal of Bioscience and Biotechnology, Vol.3,Issue. 1, pp.79-87,2014.

[4]. Gordana R Dimic, "Characteristics of the Leuconostoc mesenteroides. Subsp.Mensenteroidesstrain from fresh vegetables”, APTIFF, Vol. 37, pp. 3-11, 2006.

[5]. Wei Zhang, Mingqi Liu, Xianjun Dai, "Biological characteristics and probiotic effect of Leuconostoc lactis strain isolated from the intestine of black porgy fish", Brazilian Journal of Microbiology, Vol. 44, Issue. 3, pp.685-691, 2013.

[6]. Suzanne Johanningsmeier, Roger, F. Mcfeeters, P. Henry, Fleming and L.Roger, "Thompson effects of Leuconostoc mesenteroides starter culture on fermentation of cabbage with reduced salt concentrations", Journal Food Science, Vol. 72, Issue. 5, pp.166 - 172, 2007.

[7]. M. Tamminen, T. Joutsjoki, M. Sjoblom, M. Joutsen, A. Palva, E.L. Ryhanen, and V. Joutsjoki, "Screening of lactic acid bacteria from fermented vegetables by carbohydrate profiling and PCR-ELISA",Letter of Applied Microbiology, Vol. 39, pp.439444, 2004.

[8]. P. Baumann, and R.H.W. Schubert, "Vibrio naceaeVeron",Bergey's manual of systematic bacteriology,pp.516-550, 1984.

[9]. S. K. Allameh, Daud, H. Yusoff, F. M. Saad, C. R. and A. Ideris, A, "Isolation, identification and characterization of Leuconostocmesenteroidesas a new probiotic from intestine of snakehead fish (ChannaStriatus)", African Journal of Biotechnology, Vol. 11, Issue. 16, pp-.3810-3816, 2012.

[10]. B. Sreelakshmi, "Molecular approaches for characterization and Determination of Pathogenecity of vibrios with special reference to vibrio harveyi from penaeusmondon larval production system", Ph.D Thesis, 2011.

[11]. R.C. Edgar, "MUSCLE: multiple sequence alignment with high accuracy and high throughput", Nucleic Acids Res, Vol. 32, Issue. 5, pp.1792-1797, 2004.

[12]. G. Talavera, and J. Castresana, "Improvement of phylogenies after removingdivergent and ambiguously aligned blocks from protein sequence alignments", Systematic Biology, Vol. 56, pp. 564-577, 2007.

[13]. A. Dereeper, V. Guignon, G. Blanc, S. Audic, S. Buffet, F. Chevenet, J.F. Dufayard, S. Guindon,V. Lefort, M. Lescot, J.M. Claverie, O.Gascuel, "Phylogeny.fr: robust phylogeneticanalysis for the non-specialist", Nucleic Acids Res. Vol. 1, pp.36, 2008.

[14]. T.C. Clarke, L.I. Black, B.J. Stussman, P.M. Barnes, R.L. Nahin, "Trends in the use of complementary health approaches among adults: United States, 2002-2012”, Natl. Health Stat. Rep, Vol. 79, pp.1-16, 2015.

[15]. V. Bell, J. Ferrão, T. Fernandes, "Nutritional Guidelines and Fermented Food Frameworks", Foods, Vol. 6, pp.65. [CrossRef] [PubMed] ,2017.

[16]. R. Karthik, C. Angelin, Pushpam. and M.C. Vanitha, "Development of Marine derived probiotic bacterial consortium for the sustainable management of Litopenaeusvannameiculture", Int. J. Advanced Research in Engineering and Tech, Vol. 6, pp. $62-75,2015$.

[17]. B. Del Re, B.Sgorbati, M. Miglioli , D.Palenzona, "Adhesion, autoaggregation and hydrophobicity of 13 strains of Bifidobacteriumlongum",Lett. Appl. Microbiol, Vol. 31, pp. 438442, 2000. 
[18]. B. Kos, J. Suskovic, S. Vukovic, M. Simpraga, J. Frece, S. Matosic, "Adhesion and aggregation ability of probiotic strain Lactobacillus acidophilus M92,J. Appl. Microbiol, Vol. 94, pp. 981-987, 2003.

[19]. M. Zago, M.E. Fornasari, D. Carminati, P. Burns, V. Suàrez, G.Vinderola, J. Reinheimer,G. Giraffa G, "Characterization and probiotic potential of Lactobacillus plantarumstrains isolated from cheeses", Food Microbiol, Vol.28, pp.1033-140, 2011.

[20]. A.H. Rickard, P. Gilbert, N.J. High, P.E. Kolenbrander, P.S. Handley, "An integral process in the development of multi-species biofilms", Trends Microbiol Bacterial coaggregation, Vol.11,pp.94-100, 2003.

[21]. A. Cebeci, C. Gurakan, "Properties of potensial probiotic Lactobacillus plantarumstrains", Food Microbiol., Vol.20, Issue. 20, pp. 511-518, 2003.

[22]. T.D.T. Nguyen, J.H. Kang,M.S Lee, "Characterization of Lactobacillus plantarumPHO4, a potential probiotic bacterium with cholesterol-lowering effects", Int.J. Food Microbiol,Vol. 113, pp.358-361, 2007.

[23]. M. Begley, C.G.M. Gahan, Hill, "The interaction between bacteria and bile”, FEMS Microbiol. Rev, Vol. 29,pp-.625-651, 2005.

[24]. S. Salminen, S, Wright, A.Ouwehand, Lactic Acid Bacteria (1). New York: Marcel Dekker, Inc, 2004.
[25]. S. Erkkilä, E. Petäjä, "Screening of commercial meat starter cultures at low $\mathrm{pH}$ and in the presence of bile salts for potential probiotic use", Meat Sci, Vol. 55, pp. 297-300, 2000.

[26]. D.H. Kim, B. Austin, "Characterization of probiotic carnobacteria isolated from rainbow trout (Oncorhynchusmykiss) intestine”, Lett. Appl. Microbiol, Vol. 47, Issue. 3, pp.141-147, 2008.

[27]. A.A. Argyri, G. Zoumpopoulou, G. Kimon-Andreas, G, "Selection of potential probiotic lactic acid bacteria from fermented olives by in vitro tests", Food Microbiology, Vol.33,Issue.1, pp.282-291, 2013.

[28]. FAO/WHO, "Report on Drafting Guidelines for the Evaluation of Probiotics in Food", FAO/WHO. Joint FAO/WHO Working Group London, Canada, 2002.

\section{Author's Profile:}

Sathyapriya. A pursued her Master's degree in Biotechnology from Bharathiar University, Coimbatore respectively in the year 2013. She is currently pursuing her Ph.D in Bharathiar University. She has published 2 research papers in reputed journals and 2 papers in conference proceedings. Further she has submitted 4 gene sequences in NCBI. The work carried out by her is mainly focused on probiotics for marine aquaculture.

Table-1

\begin{tabular}{|l|l|}
\hline BiochemicalTests & Results for Probiotic \\
\hline Shape & Round \\
\hline Gram Staining & $+\mathrm{Ve}$ \\
\hline Spore Staining & Non Spore forming \\
\hline Motility & Motile \\
\hline Capsule & Non Capsulated \\
\hline Flagella & Non Flagellated \\
\hline Indole & $-\mathrm{Ve}$ \\
\hline MR & $+\mathrm{Ve}$ \\
\hline VP & $-\mathrm{Ve}$ \\
\hline Citrate & $-\mathrm{Ve}$ \\
\hline H2S production & $-\mathrm{Ve}$ \\
\hline Urease production & $-\mathrm{Ve}$ \\
\hline Gelatin hydrolysis & $-\mathrm{Ve}$ \\
\hline Nitrate reduction & $+\mathrm{Ve}$ \\
\hline Oxidase test & $-\mathrm{Ve}$ \\
\hline Glucose & $+\mathrm{Ve}$ \\
\hline Lactose & $+\mathrm{Ve}$ \\
\hline DNase & $+\mathrm{Ve}$ \\
\hline Sucrose & $+\mathrm{Ve}$ \\
\hline Catalase & $-\mathrm{Ve}$ \\
\hline Casein & $-\mathrm{Ve}$ \\
\hline Starch & $-\mathrm{Ve}$ \\
\hline Fructose & $+\mathrm{Ve}$ \\
\hline Dextrose & $+\mathrm{Ve}$ \\
\hline & \\
\hline
\end{tabular}




\begin{tabular}{|l|l|}
\hline Galactose & $+\mathrm{Ve}$ \\
\hline Xylose & $+\mathrm{Ve}$
\end{tabular}

Fig-1 Isolation of probiotics

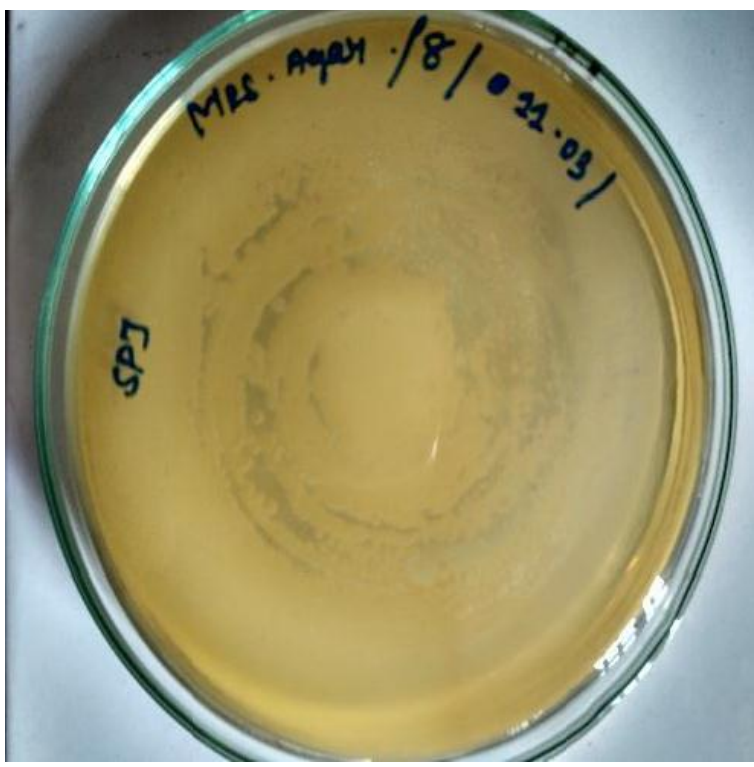

Fig-2 Molecular Identification

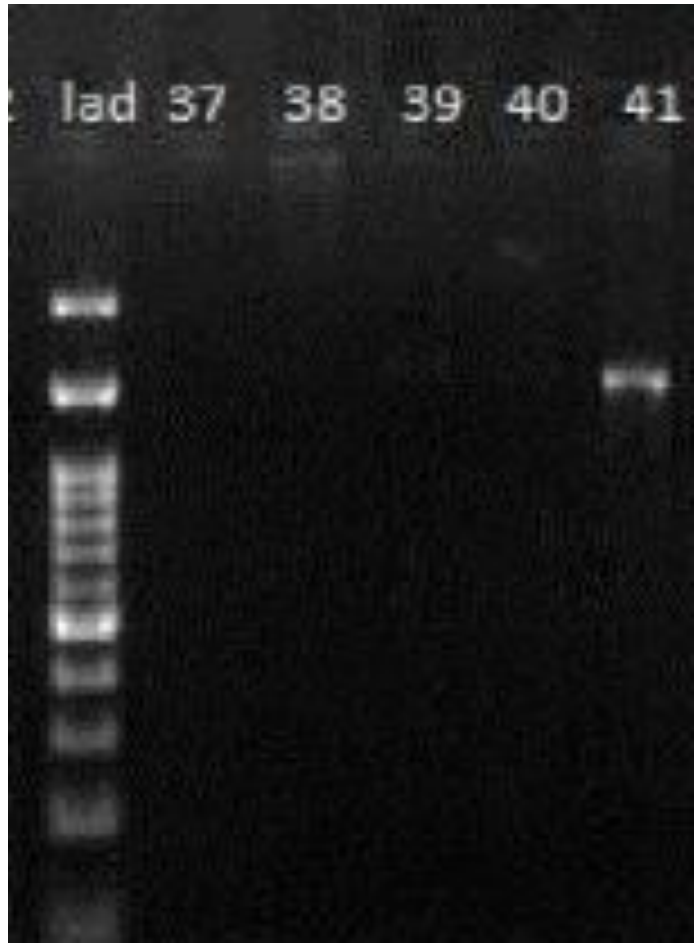


Fig-3 Hydrophobicity \& Lysozyme

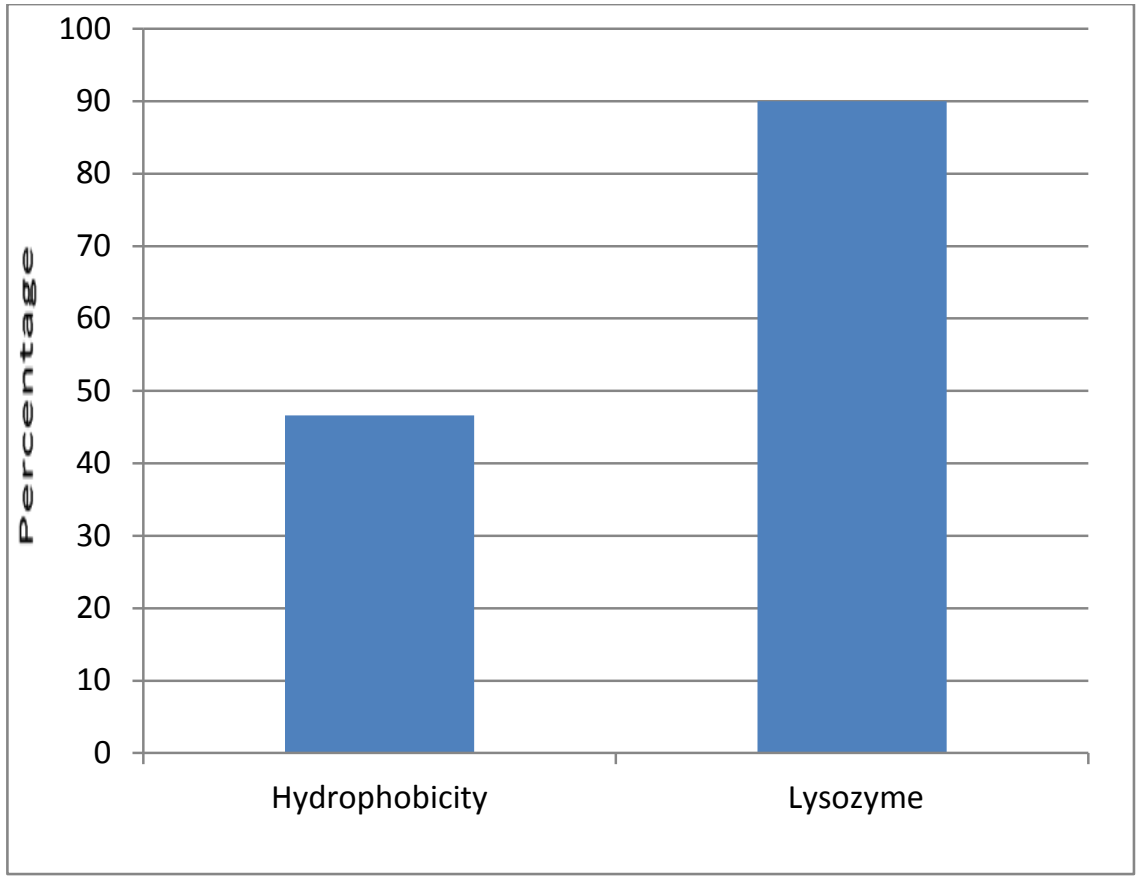

Fig-4 Autoaggregation \& coaggregation

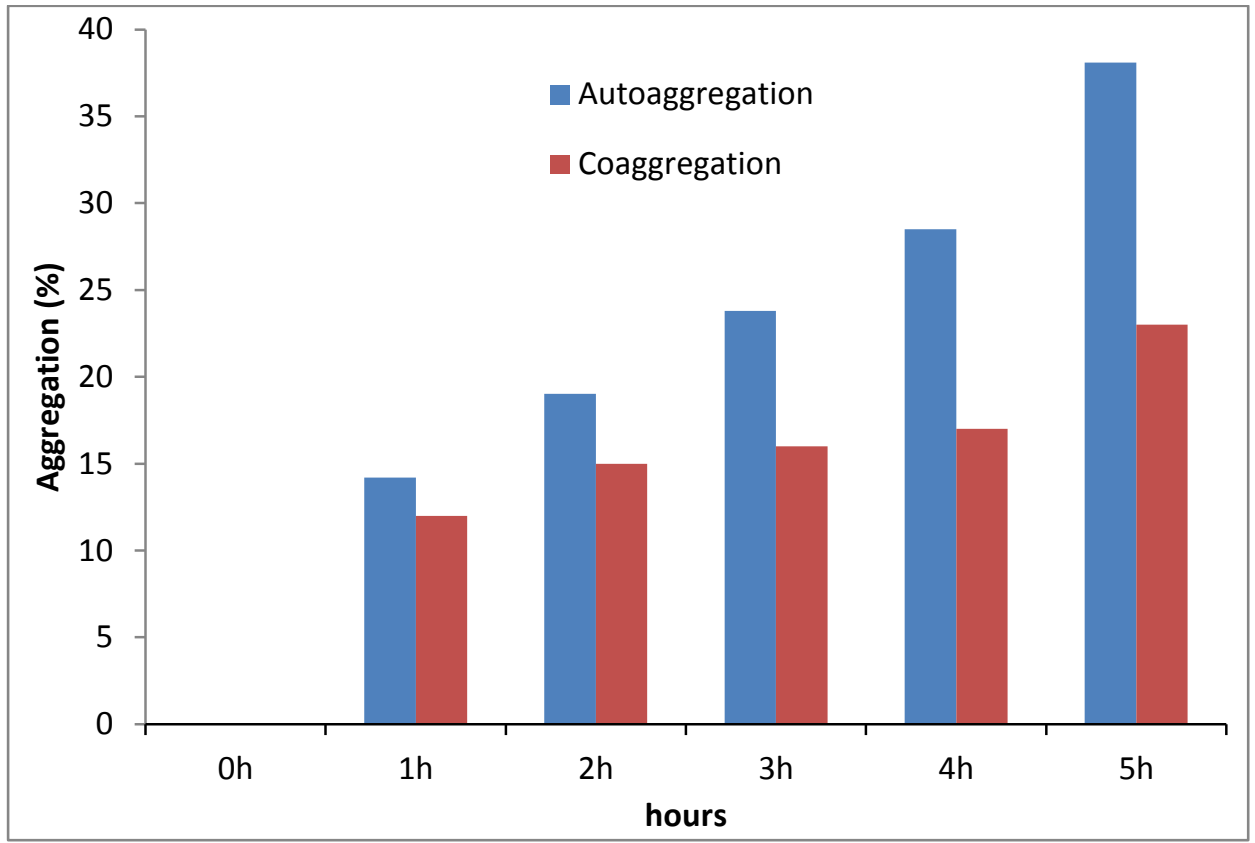


Fig-5 Bile salt tolerance

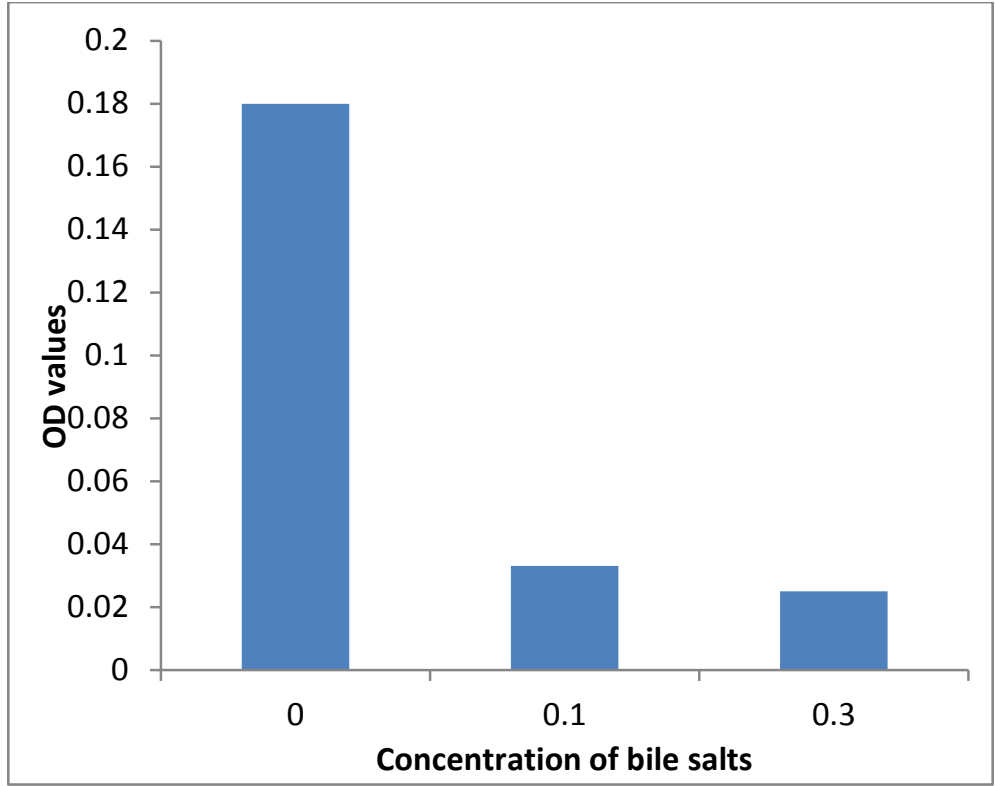

Fig-6 Effect of pH

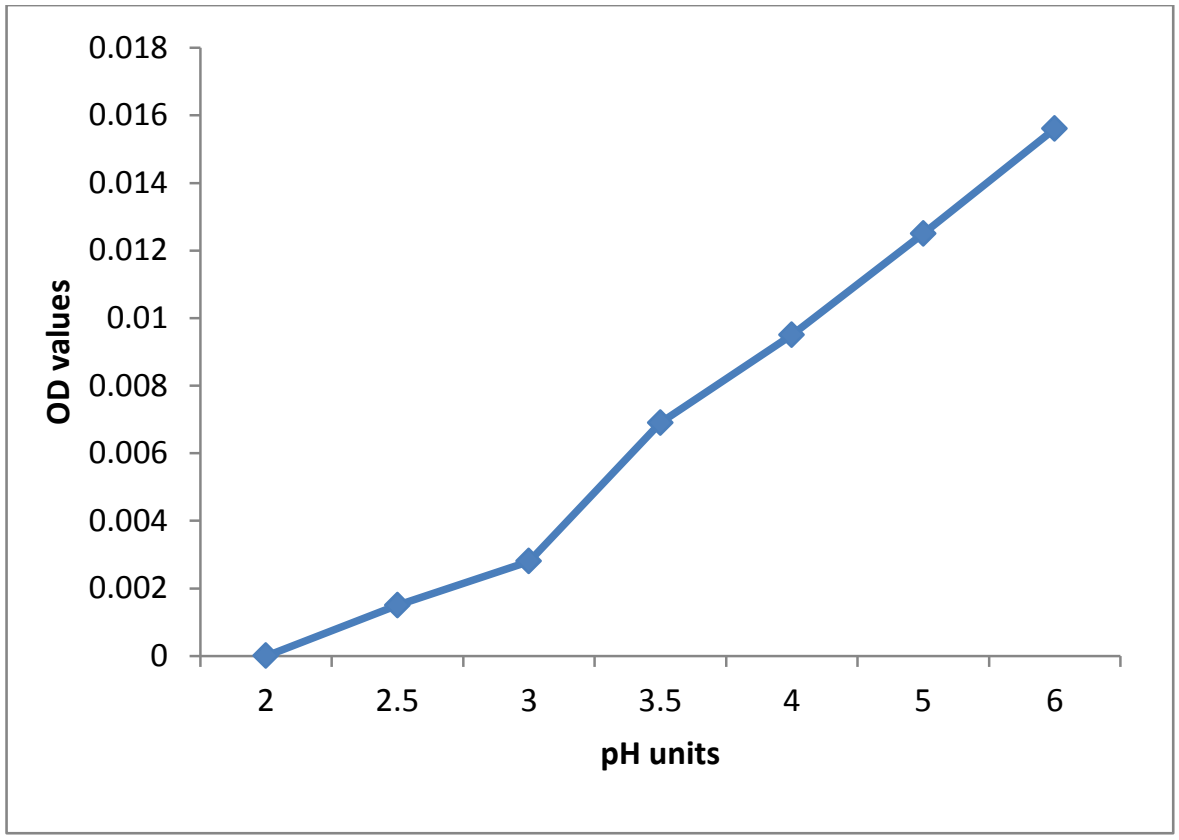

